\title{
MI ROSALÍA
}

\section{Luis Alberto de Cuenca}

Instituto de Lenguas y Culturas del Mediterráneo y Oriente Próximo

doi:10.17075/rcsxxi.2014.049

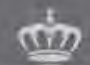

= CONSELLO

(t) DA CULTURA

GALEGA 

Álvarezz, R. / A. Angueira / M. C. Rábade / D. Vilavedra (coords.) (2014): Rosalía de Castro no século xXi. Unha nova ollada, Santiago de Compostela, Consello da Cultura Galega. doi:10.17075/rcsxxi.2014. pp. 888-897

Creo que es muy importante para Galicia y para Espańa entera conmemorar la aparición en 1863 de ese libro, Cantares gallegos. Es un momento en el que se impone ese tipo de acercamientos a la poesía popular. No olvidemos que el siglo XIX es el siglo de la gran recuperación del folklore. Pensemos que a finales del XVIII ya Percy, en Inglaterra, había publicado sus Reliques of Ancient English Poetry, que es una gran recopilación de poesía popular, y que empezaban los hermanos Grimm, por ejemplo, a acercarse a los informantes más ancianos de la comarca alemana en que vivían para que les narrasen los cuentos que luego recogerían en sus Kinder- und Hausmärchen, aparecidos precisamente en 1812, una efeméride que hemos celebrado hace bien poco. Afanásiev, en Rusia, también se acerca al mundo folklórico de su país, tan rico en cuentos y leyendas. Al margen de que era una extraordinaria poeta, una creadora increíble, de lo que no cabe duda es de que en Cantares gallegos hay mucho de folklorismo. De repente, Rosalía, que había vivido con intensidad los dramas de la Galicia profunda, como la emigración o la explotación de los gallegos por patronos de otras partes de España, se rebela contra eso, pero, a la vez, también quiere aproximarse a la sabiduría popular encarnada en esas coplas que habían enriquecido tanto la lírica galaicoportuguesa en la Edad Media y que habían pasado largos siglos de literatura oculta, que mediaban entre ese floruit y la situación lamentable en que se encontraba la lengua gallega en el momento en que se publican los Cantares. Rosalía se acerca a los cantares que dice el pueblo y los reutiliza, hace una especie de remaniement material impresionante en sus poemas, pero, realmente, Cantares gallegos todavía no es un libro auténticamente personal, sino un libro que inicia la ruta de lo personal. Hay aquí estudiosos mucho más expertos en el tema que yo que, a lo peor, me contradecirán, pero, en cualquier caso, lo que yo tengo muy claro es que, en mi lectura de la poetisa gallega, Rosalía de Castro empieza a ser personal, verdaderamente personal, solo a partir de Follas novas.

Cantares gallegos es un libro decisivo. Por eso lo estamos celebrando aquí, pero importantísimo, sobre todo, para la cultura gallega, para la lengua gallega, que nace en ese momento al mundo, porque había algún balbuceo anterior en la 
época de los 50, después madurará en la década de los 80 con la obra de Pondal o la obra de Curros, pero, realmente, en el año 63 era una revolución para la lengua gallega escribir en gallego, en un gallego no normalizado todavía, porque era impensable en aquel momento. Lo comentaba con Ángel Basanta esta mañana y voy a cerrar mi intervención con un poema de Cantares gallegos recitado en gallego, ya sabrán perdonarme, y nos referíamos al tema de la pronunciación, el ceceo, el seseo, quien sabe como leería Rosalía sus versos. Parece ser que ella seseaba; en cualquier caso, lo que sí es cierto es que la lengua que utiliza Rosalía es una lengua viva, es una lengua sin mediatizaciones gramaticales o académicas, es una lengua que surge del pueblo y que ella convierte en arte, porque ella era una mujer con una prodigiosa capacidad literaria, con una capacidad de convertir en literatura algo que, en boca del pueblo, sin su intercesión, no dejaba de ser una copla sin mayor interés. Ella, de repente, lo recupera como aquellos anónimos, o no tan anónimos, autores que en el siglo xv retoman las viejas piezas del romancero viejo y las convierten en arte porque eran ya unos grandes artistas. Desconfien de quien les diga que hay un arte colectivo. El arte es siempre individual, siempre hay una persona y un nombre propio detrás de cada pieza y, en ese sentido, el romancero es obra de una serie de personas con nombres y apellidos, cuyos nombres se han perdido evidentemente. Luego sí que hay una modificación popular de esos materiales, pero no cabe duda de que la creación es personal e intransferible y obedece a unos nombres propios determinados.

Rosalía retoma todo el caudal increíble del folklore gallego contemporáneo que ella ha oído de labios de los más viejos del lugar —o de los no tan viejos, porque entonces está vivo ese folklore- y que convierte en un libro memorable. La del año del Señor de 1863 es una fecha importante para la literatura española, evidentemente para la literatura gallega, pero también para la literatura española. La vocación de España es ser plural, y es obvio que nos enriquecemos con el aporte de las distintas lenguas españolas. Por lo que, con toda evidencia, también para la literatura espańola es 1863 una fecha muy relevante.

No olvidemos que la tradición que venía del Medievo era muy poderosa, que en un determinado momento ni más ni menos que un rey de Castilla, Alfonso X, utilizó el gallego para componer sus Cantigas. Es muy importante porque revela el prestigio que tenía la lengua gallega en el siglo xiII y es evidente que hay un puente directo entre esa lengua literaria gallega medieval y Rosalía de Castro, que 
la retoma, que la relanza en ese Rexurdimento que viene a equivaler a la Renaixença en Cataluña, siendo ambos movimientos importantísimos para la cultura española, porque lo que hacen es enriquecerla poderosamente desde la periferia.

Rosalía nació un 24 de febrero de 1837 —debo decirles que eso a mí me enternece, y por eso digo la fecha, porque mi hija Inés nació también un 24 de febrero, pero en el caso de mi hija Inés no fue tan complicado el tema de su nacimiento - como hija natural de un sacerdote. Hay otro momento decisivo en su vida, y es el encuentro con Manuel Murguía. Un encuentro que se ha discutido muchísimo dónde pudo producirse. Vosotros sabéis todas las teorías al respecto, pero parece que pudo ser en Madrid. Es importante ese momento porque Murguía, aparte de hacerle siete hijos a Rosalía — que se dice pronto que le diera tiempo a escribir tanto y tan bien con siete niños, aunque uno murió joven y otro murió prácticamente en el momento de nacer, pero son muchos nińos, en cualquier caso-, también la animó mucho a escribir, en una época en la que las mujeres no estaban acostumbradas a que los maridos las animaran a escribir, sino más bien a todo lo contrario. Hay casos especiales, estoy pensando en la literatura inglesa, en una novelista que yo admiro mucho, Ann Radcliffe, que en los últimos ańos del siglo XVIII compuso una serie de novelas góticas apasionantes y que también era alentada por su marido, el señor Radcliffe, para que las escribiera. Pero, en cualquier caso, Murguía era un hombre erudito, un hombre sabio, un hombre muy centrado en el mundo gallego, y animó mucho a Rosalía para que escribiera. Yo creo que ese espíritu folklórico de Rosalía le pudo venir de nuestro amigo Murguía, el mismo que luego iba a ser prologuista de la primera obra de Valle-Inclán, Femeninas, de 1895.

Rosalía murió muy joven de un cáncer de útero. Fue una desgracia tremenda. Esa cercanía de la muerte, esa muerte temprana de Rosalía hace que sus dos grandes libros, que yo creo que son Follas novas y En las orillas del Sar (de este último libro hay una edición estupenda en Castalia de mi amiga Marina Mayoral). Son superiores a Cantares gallegos en literatura, en literatura personal, pero los Cantares gallegos tienen un valor simbólico, trascendental, en las letras gallegas y en las letras españolas, como he dicho antes. De modo que podemos decir que una autora que, aparte de esos tres grandes libros de versos y algunos versos aislados que se han recuperado en la edición, a cargo de Marina Mayoral, que ha visto la luz en la Biblioteca Castro, también tiene una prosa nutrida e importante. 
Ahí tenemos la edición de la Biblioteca Castro tan deliciosa, pero en la que está prohibido poner notas, que es una pena, pero que no importa tanto en el caso de Rosalía, porque se lae entiende muy bien. (Imaginaos, sin embargo, lo que ocurre con los tomos dedicados en dicha colección al Marqués de Villena, de los no hay quien entienda absolutamente nada por no llevar anotaciones, pero esa fue la voluntad del fundador de esa Biblioteca). En cualquier caso, no solo resplandecía Rosalía en esa tarea poética y en esos dos grandes libros, Follas novas y En las orillas del Sar, en los que Rosalía nos contagia de una melancolía muy cercana a lo que significó, en principio, el término melancolía, o sea, lo que hoy llamamos depresión. Rosalía debió pasarlo mal en los últimos años de su vida no solo por su enfermedad, sino, en general, porque se plantearía el porqué de muchas cosas y sospecho que también por su propia naturaleza de mujer en un mundo para hombres. Yo intuyo que Rosalía sufrió mucho en la vida porque se le nota en Follas novas y En las orillas del Sar.

En una antología que yo hice en 1998, que se llamó Las cien mejores poesías de la lengua castellana y que hice de memoria, porque esas cosas hay que hacerlas así con carińo y de memoria y con los versos que se le ocurren a uno en ese momento (decía Platón que el conocimiento es recuerdo), incluí, por supuesto, a Rosalía, concretamente un poema de En las orillas del Sar, y lamentablemente me hubiera gustado traerlo para leerlo al final, junto con el poema de Cantares gallegos, pero se me ha olvidado. He venido con mucha premura y no he podido coger el libro. La verdad es que no me acuerdo de qué poema es y no voy a poder leerlo, pero no supuso para mí ningún tipo de misión fácil el elegir entre la obra castellana de Rosalía. Lo primero que publicó en castellano fue La flor (1857), un cuadernillo hoy inencontrable que suscitó la admiración que Murguía, que se casaría con ella un año después, en 1858. En ese pequeño folleto, que yo no creo que llegue ni siquiera a la consideración de libro, figuran sus primeros vagidos en lengua castellana. En las orillas del Sar muestra ya una Rosalía en castellano mucho más madura. Me fue muy complicado encontrar solo una pieza, porque decidí que en Las cien mejores poesías de la lengua castellana hubiera solo una pieza de cada uno de los poetas, al objeto de ampliar el abanico de poetas incluidos en ella.

Algo importante que quiero comentar es el tema de la recepción de Rosalía, al que ya ha aludido mi amigo Luis García Montero en una conferencia. He visto que ha hablado, sobre todo, de poetas, y quizá no se ha fijado en que Rosalía, en 
el momento en que Leopoldo Alas Clarín publica La literatura en 1881, que era una especie de fotografía de la literatura española del momento, no cita a Rosalía. Tendrían que venir los autores del 98 para reivindicarla. En Galicia, lógicamente, siempre tuvo su nicho de conocimiento, pero me refiero al resto de España. Fueron Azorín y Unamuno los grandes difusores y valedores de la obra de Rosalía de Castro. Le dedicaron una serie de artículos que versaron sobre ella y realmente reivindicaron su papel, sobre todo, en la transmisión de la antorcha de la poesía contemporánea en España, en la que yo creo que Rosalía, junto con Bécquer, tiene un papel primordial. Hay una genealogía, un pedigrí muy claro de la poesía española contemporánea. Ese pedigrí nace con Bécquer y Rosalía.

Bécquer muere en 1870 y en el 71 sus amigos, por suscripción amistosa entre un grupo de gente, publican los dos tomos de sus obras. Allí, por ejemplo, se publican por primera vez la mayor parte de sus Rimas, aunque algunas se habían publicado antes en revistas y en periódicos. Poco después, en 1880, se publica Follas novas de Rosalía. Y en el 84, En las orillas del Sar. ¿Qué quiere decir esto? Que en ese momento se está gestando la poesía española contemporánea. ¿Cuáles son los eslabones de esa cadena? El primero lo configuran Bécquer y Rosalía de Castro. El segundo, sin duda, Rubén Darío, un señor que no es español, que viene de Nicaragua, pero que resulta ser un eslabón fundamental en la modernidad poética española. Después vuelve a bifurcarse la cosa y tenemos a Antonio Machado y a Juan Ramón Jiménez. Después viene la Generación del 27, que tampoco fue ajena a los encantos de Rosalía. Un ejemplo: imagino que Luis hablaría in extenso de los Seis poemas galegos de Federico. Federico había leído a los autores trovadores galaicoportugueses del Medievo: a Martín Códax, a Mendiño, a Pero Meogo, a Paio Gómez Chariño, a toda esa pléyade que, verdaderamente, fue importantísima en la configuración de la lírica tradicional europea. Los había leído, los había degustado, pero también había leído a Rosalía. Los Seis poemas galegos, que se publicó con prólogo de Eduardo Blanco-Amor en el 35, es un libro que procede de diferentes amores: del amor por la poesía galaicoportuguesa medieval, del amor por la poesía de Rosalía, por otro lado, y del amor por la poesía portuguesa de Camóes, que como sabe todo el mundo escribió algunos versos memorables en español en el siglo XVI, y por la poesía cancioneril castellana de Gil Vicente, que había editado un íntimo amigo de Federico, ni más ni menos que Dámaso Alonso, en la editorial Signo (Gil Vicente es otro poeta extraordinario en 
portugués y en español, pero en poesía sobresalió, sobre todo, en la lengua común de los españoles). Digamos que su admiración no solo por Rosalía sino también por Eduardo Pondal o Manuel Curros Enríquez, y por esas otras corrientes que confluyeron en su gusto, le hizo escribir en gallego seis poemas extraordinarios. Es el libro, por cierto, más difícil de encontrar de García Lorca. Hay coleccionistas de Lorca que tienen todas sus primeras ediciones menos esa, que es rarísima.

Mi única aportación a este Simposio es la aportación de un poeta que leyó, o más bien devoró, a Rosalía de Castro en la edición de Aguilar, colección Joya (con sus preciosos cortes pintados), en la biblioteca paterna. Debo reconocer, en cambio, que no conozco su prosa narrativa, El caballero de las botas azules y todo eso. Pero su poesía me parece maravillosa, con una desnudez, una capacidad de comunicar desolación que, sobre todo, en la adolescencia, cuando estamos tan necesitados en nuestra desolación adolescente de encontrar modelos para profundizar en nuestra enorme condición de desamparados (porque la adolescencia es una época de desamparo), me ayudó mucho, leída en aquel tomo de la colección Joya de Aguilar. Luego supe que había sido un eslabón importante en la cadena de la poesía española contemporánea, pero eso era lo de menos, lo de más es que me sirvió en un determinado momento, junto con otro volumen de la colección Joya que iba dedicado a Bécquer, con un prólogo de los hermanos Quintero, a superar la difícil etapa de la adolescencia.

Voy a terminar mi intervención, y esta es la prueba del nueve porque voy a leerlo en gallego, un poema de Cantares gallegos que me gusta muchísimo, aquel que dice:

\footnotetext{
Pasa río, pasa río,

co teu maino rebulir, pasa, pasa entre as froliñas color de ouro e de marfil, a quen cos teus doces labios tan doces cousas lles dis. Pasa, pasa, mais non vexan que te vas ó mar sin fin porque entonces ¡ai, probiñas, canto choraran por ti!
} 
¡Si souperas que estrańeza,

si souperas que sufrir

desque del vivo apartada

o meu corazón sentiu!

Tal me acoden as soidades,

tal me queren afrixir

que inda máis feras me afogan,

si as quero botar de min.

I ¡ai, qué fora das froliñas

véndote lonxe de si

ir pola verde ribeira,

da ribeira do Carril!

Pasa, pasa, caladińo,

co teu manso rebulir,

camiño do mar salado,

camiño do mar sin fin;

e leva estas lagrimiñas,

si has de chegar por alí,

pretińo do meus amores,

pretiño do meu vivir.

¡Ai, quen lagrimiña fora

para ir meu ben, unda ti!...

¡Quen fixera un camiñińo

para pasar, ai de min!

Un poema que finaliza con esta copla popular:

Si o mar tivera barandas

fórate ver ó Brasil;

mais o mar non ten barandas,

amor meu, ¿por donde hei de ir?

Rosalía fue capaz de entender algo que para un poeta está siempre claro, que la poesía de corte tradicional es la poesía de corte popular, pero que nunca es colec- 
tiva, que es individual, aunque se nos haya transmitido colectivamente. Nunca ha habido otra poesía tan profunda y tan emocionante y que suscite tanto ese sentimiento que experimentamos al leerla. Repito, para terminar: «Si o mar tivera barandas / fórate ver ó Brasil; / mais o mar non ten barandas, /amor meu, ¿por donde hei de ir?».

Esa melancolía es la que ocupó la vida de Rosalía en sus últimos años y a lo largo de toda su existencia, porque sin melancolía tampoco hay verdadera poesía. 